\title{
O valor da percepção do corpo para o conhecimento do espaço cênico: uma contribuição para a preparação vocal de atores de teatro baseada no pensamento de Merleau-Ponty
}

\author{
The value of the body's perception for the knowledge of \\ the scenic space: a contribution for the theater actor's \\ vocal preparation based in Merleau-Ponty thought
}

Rosângela Gonçalves ${ }^{1}$

Iris Lima e Silva ${ }^{2}$

Fabrício Cardoso

Heron Beresford ${ }^{4}$

RESUMO: Segundo Merleau-Ponty, a interação dos sentidos para a percepção é a base do conhecimento intuitivo. $\mathrm{O}$ autor nos faz ver que o corpo é a nossa principal referência espacial e que o espaço deve ser compreendido não só a partir dele, mas também como sua própria extensão, em uma compreensão fenomenológica, apoiada na experiência corporal e vivencial. Sendo o conhecimento do espaço cênico aspecto essencial para o ator de teatro bem projetar a sua voz, este artigo teve por objetivo avaliar o papel da percepção neste sentido, com o propósito de contribuir para a preparação vocal desses profissionais. Para assegurar a consecução de tal obje-

\footnotetext{
1 Fonoaudióloga, preparadora vocal da Escola de Teatro Martins Pena Funarj e da Casa de Artes de Laranjeiras - CAL, mestranda em Ciência da Motricidade Humana/ Universidade Castelo Branco - RJ.

2 Mestre em Ciência da Motricidade Humana/ Universidade Castelo Bran$\mathrm{co}-\mathrm{RJ}$ e pesquisadora do LABFILC - UCB-RJ.

3 Mestre em Ciência da Motricidade Humana/ Universidade Castelo Branco - RJ e pesquisador do LABFILC - UCB-RJ.

4 Doutor em Filosofia - UGF-RJ, Professor Titular do Programa de PósGraduação em Ciência da Motricidade Humana - UCB-RJ, Professor Adjunto da Universidade do Estado do Rio de Janeiro - Uerj e coordenador de Pesquisas no LABFILC - UCB-RJ.
}

tivo, foi realizado um estudo exploratório, operacionalizado por meio de uma pesquisa bibliográfica. Concluiu-se que a percepção do corpo, como primeira via de acesso ao mundo e, portanto, como fulcro central para apreender a realidade, mostra-se como um valor para atores de teatro conhecer o espaço cênico e bem projetar a voz.

Palavras-chave: percepção do corpo; espaço cênico; preparação vocal de atores de teatro; Merleau-Ponty; valor.

ABSTRACT: According to Merleau-Ponty, the sense's interaction to perception is the basis of intuitive knowledge. The author makes us see that the body is our main reference space and that space must be understood not only from him, but also as his extension, in a phenomenological vision, based on the bodily experience and perception. As the knowledge of the scenic space is essential to a good projection of the theater actors' voice, this article aims to evaluate the role of perception for this, to contribute for voice preparation. We carried out an exploratory study through a literature search. It was concluded that the body's perception, as the first access to the world and, therefore, as central fulcrum to apprehend the reality, it reveals as a value for theater actors to knowledge the scenic space and to project the voice well.

Keywords: body's perception; scenic space; theater actor's vocal preparation; Merleau-Ponty; value. 


\section{Introdução}

A encenação é a concretização do texto por intermédio do ator e do espaço cênico, numa duração vivenciada pelos espectadores. Teatralizar um acontecimento ou um texto é interpretar, usando cenas e atores para construir uma determinada situação. Portanto, o ator passa a existir juntamente com o teatro, desempenhando um papel ou encarnando um "personagem". Ele situa-se, pois, no próprio cerne do acontecimento teatral, sendo o vínculo vivo entre o texto do autor, as diretrizes de atuação do encenador (diretor) e o olhar e a audição do espectador (PAVIS, 2007).

Para representar, o ator retira do seu interior (espaço pessoal) as intenções, sensações e emoções, que ultrapassam seu corpo e atingem todo o espaço cênico (palco e platéia) por meio da sua voz, com o único objetivo de abraçar sonoramente todos os espectadores. Isto é um desafio, pois, muitas vezes, ele representa pessoas muito diferentes e distantes da sua história de vida: vozes diferentes, gestos diferentes, atitudes opostas (BEUTTENMÜLLER, 1995).

Quanto a isso, a atriz Marília Pêra (2008) diz que, no início de sua carreira, era um desafio interessante colocar o corpo, a alma e os sentimentos à disposição de personagens tão diferentes. Esta exteriorização do espaço interior é uma obsessão das atuais pesquisas sobre o ator, pois, segundo Pavis (2007), a verdadeira fruição da obra poética provém da liberação de tensões de nossa alma. Liberação que se dá pelo corpo e pela vOZ - esta, uma assinatura íntima do ator.

A fonação é uma habilidade adquirida pela espécie humana. Com a evolução, o homem aprendeu a coordenar órgãos que, anatômica e fisiologicamente, apresentavam como funções primordiais a alimentação, a respiração e a proteção das vias aéreas inferiores. Deste modo, a voz humana, apesar de sua beleza e aprimoramento, é uma função adaptada e, como tal, depende da integridade e do equilíbrio de estruturas e mecanismos do trato vocal. As pregas vocais, uma destas estruturas, podem ser acometidas por vários distúrbios, sendo a rouquidão funcional um dos problemas mais comuns (PINHO, 2001).

Esse problema da rouquidão pode ter diferentes causas, destacando-se dentre elas a falta de hidratação, o uso de cigarros, de álcool ou de alguns medicamentos, postura ou respiração inadequada, quadros alérgicos, sentimentos e emoções negativas, tais como medo, insegurança e tristeza. Todavia, tal problema é causado principalmente pelo uso excessivo da vOz (BERNHARD, 1988; GONÇALVES, 2000; PINHO, 2001; BRITO, 2004).
Por isso, Beuttenmüller e Laport (1974) dizem que a "quantidade de voz" mobilizada por um ator em um determinado espaço cênico, que é representado pelo palco e pela platéia, é causa importante para os distúrbios de voz. O excesso de volume, a falta de volume, o sussurro mal efetuado e até mesmo o uso da comunicação não-verbal de forma errada, forçando o movimento laríngeo da fala sem falar, causam fadiga vocal, sendo motivos freqüentes da rouquidão.

Assim, para manter a saúde vocal, o ator de teatro deve ter conhecimento e domínio do seu corpo, da sua voz e do espaço cênico, para assumir a construção do personagem que vai representar (BEUTTENMÜLLER; LAPORT; 1974).

Porém, a questão do corpo como elemento central da problemática da percepção, e, portanto, no âmbito do tema do conhecimento, necessita ser mais bem discutida. Por isto, este artigo teve por objetivo avaliar o papel da percepção no conhecimento do espaço cênico, com o propósito de contribuir para a preparação vocal de atores de teatro.

\section{Metodologia}

Para assegurar a consecução do objetivo descrito, foi realizado um estudo exploratório, operacionalizado por meio de uma pesquisa bibliográfica, por ser esta uma estratégia extremamente adequada para rever, analisar, interpretar e criticar considerações teóricas ou paradigmas, e mesmo para criar novas proposições de explicação e de compreensão dos fenômenos das mais diferentes áreas do conhecimento, podendo, inclusive, fundamentar futuras investigações descritivas e experimentais (LAKATOS; MARCONI; 1991).

\section{A percepção no pensamento de Merleau-Ponty}

Em sua obra Fenomenologia da percepção, a qual vai nos servir de base para discorrer sobre o presente tema, Merleau-Ponty (1999) enfoca o conhecimento do corpo próprio, ou do próprio corpo, como sendo o fulcro central da problemática da percepção, por considerar que o pensamento objetivo ignora o sujeito da percepção. Para o referido autor, a percepção é sempre consciência perceptiva de alguma coisa e, nela, não se pode separar o sujeito e o objeto, porque aquele é uma potência que se sincroniza com o meio, em uma atitude voluntária, intencional, reportando-se a um ser exterior por uma sensação única e exclusiva do momento. 
A sensação é a maneira pela qual o sujeito é afetado, representando a experiência de um estado de si mesmo que se manifesta a partir da sensibilidade que a precedeu. É sempre espacial porque, como contato primordial do sujeito que sente com um ser exterior que faz parte de uma forma de existência indicada pelo sensível, ela própria é constitutiva de um meio de experiência, ou seja, um espaço.

No mundo objetivo, a sensação é tida como um processo neurofisiológico de ligação do organismo com o meio, através dos órgãos sensoriais, e consiste na transmissão de um influxo nervoso, corrente elétrica que percorre os nossos nervos desde o órgão sensorial até os centros de decodificação.

Tal fato realiza-se pela ação de um estímulo específico sobre um receptor que é apropriado para recebê-lo. Entreve-se, no entanto, no grau elementar da sensibilidade, uma colaboração dos estímulos parciais entre si e do sistema sensorial com o sistema motor que, em uma constelação de neuromotricidade variável, mantém constante a sensação.

Apreende-se, assim, a sensação na perspectiva dos fenômenos corporais que a preparam, impedindo a definição do processo nervoso como a simples transmissão de uma mensagem dada. A hipótese de constância, pois, entra em conflito com os dados da própria constância, mostrando um caráter puramente teórico. Ocorrem casos em que o fenômeno, o percebido, não adere ao estímulo. Isto quer dizer que fatores adicionais - atenção e juízo - modificam o fenômeno.

Quando a grandeza aparente de um objeto varia com sua distância aparente, ou sua cor aparente com as recordações que dela temos, reconhece-se que os processos sensoriais não são inacessíveis a influências centrais. O sensível, assim, não pode mais ser definido como o efeito de um estímulo exterior e a lei da constância não pode prevalecer contra o testemunho da consciência.

A atenção é a função que revela as sensações, assim como um projetor ilumina objetos preexistentes na sombra, fazendo jorrar a percepção, a interpretação do objeto. A percepção, pois, é um juízo, inclusive com a conotação axiológica; uma ligação lógica de um predicado a algo, implicando sempre uma "pretensão de verdade". Por isto, envolve sempre a necessidade do ato de reflexão, uma vez que:

Quando olho rapidamente os objetos que me circundam para me situar e orientar entre eles, mal tenho acesso ao aspecto instantâneo do mundo; identifico aqui a porta, ali a janela, mais adiante a minha mesa, que são apenas os suportes e os guias de uma intenção prática orientada em outra direção, e que agora só me são dados como significações. Mas, quando con- templo um objeto com a única preocupação de vê-lo existir e desdobrar diante de mim as suas riquezas, então ele deixa de ser uma alusão a um tipo geral, e eu me apercebo de que cada percepção, e não apenas aquela dos espetáculos que descubro pela primeira vez, recomeça por sua própria conta o nascimento da inteligência e tem algo de uma invenção genial: para que eu reconheça a árvore como árvore, é preciso que, abaixo desta significação adquirida, o arranjo momentâneo do espetáculo sensível recomece, como no primeiro dia do mundo vegetal, a desenhar a idéia individual desta árvore (p. 74-75).

A reflexão busca a essência da percepção, declarando que esta não é presumidamente verdadeira, mas que representa o acesso à verdade. A percepção abre-se sobre as coisas, mas é o interiorizar e refletir que trará a percepção do mundo verdadeiro e exato pela razão; é o ser-no-mundo, no tempo e espaço que desvendará a verdade.

Torna-se, então, impossível separar o inteligível do empírico ou do sensível, pois este fornece a base para a atuação racional. Desta forma, a percepção não é aquilo que pensamos, mas aquilo que vivemos, uma vez que estamos abertos ao mundo e comunicamo-nos indubitavelmente com ele pelo nosso corpo. Pontua-se, assim, o papel da consciência para o corpo-próprio, evidenciando-se que o homem é uma consciência encarnada que concretiza sua intencionalidade com a intermediação do corpo. Portanto, seus movimentos são portadores de significado, ou com valor existencial, por estarem vinculados ao ser no mundo. O corpo, assim, não é um objeto, nem seu movimento um simples deslocamento no espaço objetivo.

A percepção é, nessa visão, uma modalidade original da consciência, e se dá dentro de um horizonte e no mundo, percebendo-se não só elementos constituídos de matéria, mas também uma forma. Ela não se dá somente no mundo das idéias, mas principalmente na experiência do mundo vivido.

Essa percepção e a ação, porém, só são nítidas em um espaço fenomenal orientado, estando o sujeito da percepção e da ação confrontado com um mundo em que já existem direções absolutas, de tal modo que ele tem que adequar as dimensões de seu comportamento àquelas do mundo.

Merleau-Ponty (ibid.) prega uma filosofia aberta para o mundo, devendo-se interpretar dentro deste seus próprios dados e o homem nele existente. Esta é a sua fenomenologia da percepção, que entende que o organismo e suas dialéticas não são estranhos à história, porque o homem não é um psiquismo unido a um organismo, mas sim um projeto que se desenvolve por 
meio de um inter-relacionamento entre psíquico/fisiológico/social e histórico. Estabelece, assim, a noção de uma consciência perceptiva solidária com o corpopróprio, ou um corpo vivido, maneira pela qual nos instalamos no mundo.

\section{A percepção e o conhecimento do espaço cênico}

Normalmente se atribui existência aos espaços e às coisas, mas, na realidade, sem nós, elas não existiriam. Sempre que se fala em conhecimento humano, envolvem-se dois termos, o sujeito que conhece ou o sujeito cognoscente, que representa, em última análise, um ente responsável por produzir um determinado conhecimento, e algo de que se tem ou de que se quer ter ciência, o objeto do conhecimento ou objeto cognoscível, que é o resultado possível de nossa atividade cognitiva (MERLEAU-PONTY, 1999).

Nessas condições, pensar um espaço como existente significa também pensar em si próprio. Pensar o espaço cênico significa pensar o ator e seu corpo que se liga àquele, como "parte da sua carne", revelando-se um conhecimento intuitivo e sensível que se dá a partir do "eu", da dimensão corporal, e que nesta perspectiva resgata as orientações do acima-abaixo, frente-atrás, esquerda-direita (idem).

O corpo é a principal referência espacial e o espaço cênico deve ser compreendido não só a partir dele, mas também como uma extensão do próprio corpo do ator, em uma compreensão fenomenológica, apoiada na experiência corporal e vivencial. Trata-se de ver o espaço como um estado de uma situação em constante mudança, na qual o indivíduo sabe onde está seu corpo e as partes que o compõem, por um saber absoluto (MERLEAU-PONTY, 1999).

Dessa maneira, o espaço corporal e o espaço exterior formam um sistema prático, no qual projetar a voz é sentir no espaço a continuação do próprio corpo. Para um ator de teatro, é lançar a voz no espaço cênico ou espaço global, com a postura adequada, a respiração necessária, a emoção desejada, e com o menor esforço vocal possível, condição necessariamente imperativa para um ator continuar em cartaz. É integrar fala e pensamento, porque é este que dá sentido àquela, sendo o pensamento e a expressão constituídos simultaneamente. A fala é, pois, um verdadeiro gesto dotado de significado ou com valor intrinsecamente agregado, por ser um gesto que é traduzido pelo corpo, tornando possível a comunicação humana, condição essencial para a encenação de peças teatrais (BEUTTENMÜLLER; LAPORT; 1974; MERLEAU-PONTY, 1999).
Porque a fala é uma das expressões de comunicação do corpo, Beuttenmüller (2003) cita alguns aspectos importantes para que atores de teatro consigam ter uma boa projeção de voz. Um destes aspectos é a postura, na qual a cabeça deve estar bem colocada em relação ao corpo, com a nuca visível, nariz como centro da fisionomia, ombros relaxados, nem baixos demais e nem elevados; pés no chão com abertura equivalente ao caminhar, língua repousada no assoalho da boca só sendo elevada para deglutir ou falar, joelhos relaxados, axilas soltas, a coluna vertebral "viva" e "pulsante". Isto significa que a coluna vertebral deve estar em suspensão quando se ouve e quando se fala; um ator não fala e esvazia. Ele permanece como atitude ou conduta; o corpo permanece em expressão.

O conhecimento do espaço cênico é um dos aspectos mais importante para o ator manter essa postura. Porém, é o sentir o próprio corpo, parado ou em movimento, mas em harmonia com aquele espaço, que desenvolve um melhor processamento de informações e de integração sensorial, ideal para se ter real domínio do espaço global que se quer atingir com a voz. Isto porque um corpo tem sua própria espacialidade que só é percebida por uma tomada de consciência da postura no mundo intersensorial, porque para o homem não haverá espaço se ele não tiver uma percepção do corpo como a própria referência de alguma perspectiva espacial, e então a voz (prolongamento do corpo) abraçará todo o espaço quando sentir ser abraçada por ele (BEUTTENMÜLLER; LAPORT; 1974; MERLEAUPONTY, 1999).

$\mathrm{O}$ ator tem que ser capaz de falar numa pequena sala de espetáculos ou num teatro de dois mil lugares. Portanto, precisa constituir o espaço do teatro no qual atuará, porque o corpo não tem poder sobre o mundo em todas as posições. $\mathrm{O}$ ato de constituir é solicitado, motivado, uma vez que toda fixação é sempre fixação de algo que se oferece como a ser fixado. No ato de constituir o espaço, a percepção e a consciência são condições indispensáveis porque o espaço, e mesmo uma direção nele traçada, só pode existir para um sujeito que a traça. Porém, no ato da percepção é preciso fragmentar este espaço para perceber e constituir com os sentidos - visão, audição, olfato, paladar, tato. Em especial com o olhar, que, como uma espécie de "faróis a iluminar", uma máquina de conhecer, apreende as coisas por onde elas devem ser apreendidas para se tornarem espetáculo (idem).

Por isto Beuttenmüller (2003) dividiu o espaço em: pessoal, que é representado pelas emoções e sentimentos; parcial, que é o espaço que o corpo ocupa no espaço; sonoro, ou a voz; e global, ou seja, todo o espaço que vai desde o início do palco até o fim da platéia; todo 
o espaço que precisa ser preenchido com a voz, ou que deve ser habitado pela voz de um ator, ou comunicador, se estivéssemos falando de um auditório.

Em uma perspectiva fenomenológica, tal qual pensada por Merleau-Ponty (1999), Beuttenmüller e Laport (1974) traçam, no espaço global, diagonais retiradas de todos os cantos desse espaço: quinas dos encontros do teto com as paredes, quinas dos encontros entre o chão e as paredes, e do encontro dessas diagonais, que se cruzam - as diferentes posições do mundo - e chegam ao centro desse espaço, ou núcleo sonoro. É justamente nessa região central que a voz deve ser lançada e de onde, através de ondas físicas, todo o espaço receberá confortavelmente a voz do ator. O exemplo, por analogia, é de um lago redondo em que se atira uma pedra em seu centro e de onde ondas arredondadas acontecerão do centro para fora, formando as diferentes posições do mundo "lago".

\section{Conclusões}

A percepção do corpo se dá no plano da consciência e, portanto, no âmbito da experiência de cada um. Permite, em geral, o primeiro acesso ao mundo, sendo particular e intransferível. Justamente por ser algo tão heterogêneo e individual não pode ter seu potencial ignorado nas escolas de formação de teatro, especialmente no processo de conhecimento acerca do espaço cênico. A percepção constitui a base para tal conhecimento que, por sua vez, é essencial para uma boa projeção de voz de atores quando da apresentação em peças teatrais.

Como um processo mental cognitivo, a percepção deve ser coordenada com outros fatores como a atenção, a memória e o raciocínio, procurando-se otimizar a interação do conhecimento que se tem intuitivamente sobre um fenômeno com as habilidades ou competências adquiridas, para que se estabeleça a aprendizagem. Para um ator de teatro, esta interação torna-se necessária, porque reconhecer de fato o espaço cênico significa transformá-lo em um fenômeno. Por sua vez, tal ato da consciência implica em uma multiplicidade de outros atos, que se inicia na sensação, passa pela percepção, representação e, findando-se em um juízo, inclusive de valor, culmina com o estabelecimento de um conceito acerca de tal espaço, onde deverá projetar a sua voz.

Concluiu-se, assim, que a percepção do corpo, como via primeira de acesso ao mundo e, portanto, como fulcro central para se apreender a realidade, mostra-se como um valor para atores de teatro conhecer o espaço cênico e bem projetar a voz.

\section{Referências}

BERNHARD, Cristiana Caribé Lima. A fonoaudiologia no teatro. In: PICCOLOTTO, Ferreira (Org.). Trabalhando a voz - vários enfoques em fonoaudiologia. São Paulo: Summus, 1988.

BEUTTENMÜLLER, Glorinha; LAPORT, Nelly. Expressão vocal e expressão corporal. Rio de Janeiro: Enelivros, 1974.

BEUTTENMÜLLER, Glorinha. O despertar da comunicação. Rio de Janeiro: Enelivros, 1995.

2003.

O que é ser fonoaudióloga. Rio de Janeiro: Record,

BRITO, Marly Santoro. A aplicação do Método Espaço-Direcional-Beuttenmüller no trabalho com atores. In: GUBERFAIN, J. C. (Org.). Voz em cena 1. Rio de Janeiro: Revinter, 2004.

GONÇALVES, Rose. A voz do ator. Caderno de Teatro, Rio de Janeiro, n. 161. p. 11-13, 2000.

LAKATOS, Eva Maria; MARCONI, Marina de Andrade. Fundamentos de metodologia cientifica. 3. ed. São Paulo: Atlas, 1991.

MERLEAU-PONTY, Maurice. Fenomenologia da percepção. São Paulo: Martins Fontes, 1999.

PAVIS, Patrice. Dicionário de teatro. 3. ed. Trad. J. Guinsburg; Maria Lucia Pereira. São Paulo: Perspectiva, 2007.

PÊRA, Marília. Cartas a uma jovem atriz. Rio de Janeiro: Campus/Elsevier, 2008.

PINHO, Silvia M. Rebelo. Tópicos em voz. Rio de Janeiro: Guanabara Koogan, 2000. 